\title{
Sonographic evaluation of diaphragmatic dysfunction in COPD patients
}

\author{
This article was published in the following Dove Press journal: \\ International Journal of COPD \\ II September 2015 \\ Number of times this article has been viewed
}

\section{Nadine Scheibe \\ Natalia Sosnowski \\ Alina Pinkhasik \\ Sandy Vonderbank \\ Andreas Bastian}

Department of Pneumonology, Marienkrankenhaus Kassel,

Kassel, Germany

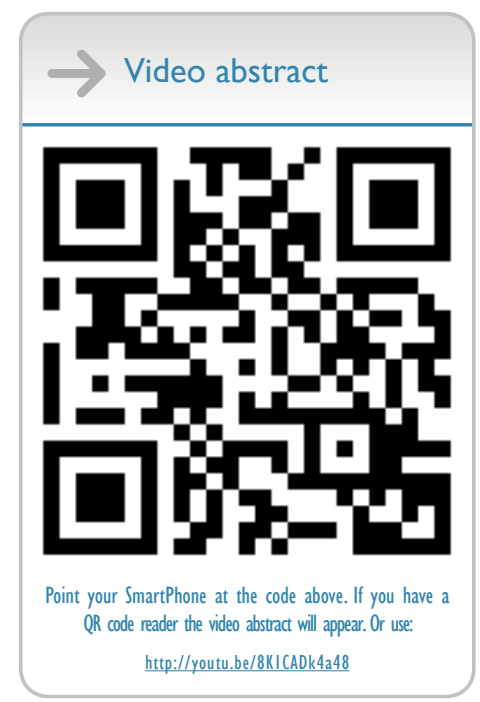

Correspondence: Andreas Bastian Department of Pneumonology, Marienkrankenhaus Kassel, Marburger Street 85, 34I27 Kassel, Germany $\mathrm{Tel}+495618073$ I2I2

Email a.bastian@marienkrankenhauskassel.de
Background: Diaphragmatic dysfunction is an important reason for dyspnea in COPD patients. But diaphragmatic dysfunction is difficult to evaluate. Ultrasound is an option. We measure sonographically the up- and downward movement of the lung silhouette on both hemidiaphragms. The aim of this prospective investigation was to compare this method with another sonographic method that visualizes the right hemidiaphragm directly and to compare the sonographic results with lung function parameters.

Methods and patients: Eighty participants -20 healthy persons and 60 COPD patients three groups each with 20 patients with COPD GOLD II, III, and IV - were investigated. The sonographic measurements of the diaphragms were performed. Lung function parameters, blood gases, and 6-minute walk test were also collected and compared to the sonographic results.

Results: The sonographic measurement of the lung silhouette was easy to perform in all study participants. The correlation between the sonographic methods measuring the right hemidiaphragmatic movement was strong $(r=0.85)$. There was also a strong correlation between the demonstrated sonographic measurement of the up- and downward movement of the lung silhouette and the forced expiratory volume in the first second $(r=0.83)$.

Conclusion: We demonstrated that the sonographic measurement of the movement of the lung silhouette is an easy way to establish diaphragmatic dysfunction in COPD patients; it can be done in all patients with reliable results for the right and the left hemidiaphragm.

Keywords: diaphragm, sonography, ultrasound

\section{Introduction}

COPD patients suffer from diaphragmatic dysfunction. There are different causes for this: a mechanical disadvantage due to overinflation of the lungs is the oldest known reason for diaphragmatic dysfunction in COPD patients. ${ }^{1-4}$ Remodeling, ${ }^{5}$ oxidative stress, ${ }^{6}$ and a reduction of myosin filaments due to a reduced protein production and an increased apoptosis of muscle cells are more recently recognized reasons for the diaphragmatic weakness. ${ }^{7,8}$

The best available method, the gold standard, for the measurement of diaphragmatic dysfunction is the measurement of the transdiaphragmatic pressure after magnetic stimulation of the phrenic nerve. ${ }^{1,9-16}$ This test is invasive and time consuming, but it is independent of the patient's cooperation. In real life, less invasive methods would be preferable. Chest radiography is not an option, and fluoroscopy is not really reliable and uses ionizing radiation. ${ }^{17}$ Computed tomography and magnetic resonance imaging can produce better results, but these methods are expensive and computed tomography uses ionizing radiation. ${ }^{18,19}$ All these methods are not practical if repeated examinations are planned. An alternative method for the measurement of diaphragmatic dysfunction is sonography. There are various sonographic methods: for example, measurement of the increasing thickening of the diaphragm in the lung apposition zone during 
contraction; ${ }^{20-22}$ the downward movement of the left portal vein during inspiration; ${ }^{23,24}$ and the direct visualization of the diaphragm from anterior with the liver or the spleen used as ultrasound windows. ${ }^{25-27}$ The main disadvantages of all these sonographical methods are that they need the patient's cooperation and that they have not really been evaluated. Which method of the sonographical ones might be the best has not yet been defined.

A different sonographic method has been preferred by us and other investigators for nearly 20 years. ${ }^{28-30}$ We do not visualize the diaphragm itself. We use the downward movement of the lung silhouette as a surrogate marker of the downward movement of both hemidiaphragms. Another important point in favor of this method is that it can easily be performed not only on the right hemidiaphragm but also on the left one.

Here we will demonstrate the sonographic method of the measurement of the distance of the up- and downward movement of the lung silhouette in COPD patients in GOLD state II, III, and IV and in healthy people.

\section{Methods}

We present here a prospective study performed between March and October 2012. The Marienkrankenhaus Ethics Committee of the hospital approved the study. All participating patients gave their informed written consent according to the Declaration of Helsinki. The study included 60 patients with COPD (20 patients each with COPD GOLD II, III, and IV) and 20 healthy volunteers. Exclusion criteria were exacerbations of COPD during the last 6 weeks, a blood gas $\mathrm{pH}<7.35$, other known pulmonary diseases besides COPD such as pleural effusion, pneumothorax, and phrenic nerve palsy, known cardiac insufficiency, and obesity (patients with a body mass index $>30$ ).

All patients had to undergo pulmonary function tests including measurement of forced expiratory volume in the first second (FEV1), vital capacity (VC), and residual volume (RV); carbon diffusion measurement, and measurement of ventilatory muscle strength (P0.1/Pimax); pulmonary blood gases were taken; and a 6-minute walk test and the sonographic examinations were done.

\section{Sonographic examinations}

Lung silhouette method: measurement of the upward and downward movement of the lung silhouette in the scapular line

All participants were evaluated in a sitting position. Ultrasound was performed with a Hitachi ultrasound system (Sono MR, EUB-7500 HV) using a 3.5 MHz curved probe.
The transducer was placed at the lowest part of the lung silhouette in the scapular line (Figure 1). The participant was instructed to exhale as deeply as possible (to RV) and then to inhale deeply to total lung capacity. This maneuver was filmed, and afterward, the distance between the highest and the lowest point of the lung silhouette was measured (Figure 2A and B). This maneuver was performed on the right and the left side. For comparison between this method and the anterior method, only the right side value was used because the anterior method was only used on the right side because of the well-known difficulties on the left side with the anterior method..$^{20,21,24,27,29}$ The median value was calculated.

\section{Anterior method: measurement of the up- and downward movement of the right diaphragmatic dome from anterior}

All participants were evaluated in a lying position. Ultrasound was performed with a Hitachi ultrasound system (Sono MR, EUB-7500 HV) using a $3.5 \mathrm{MHz}$ curved probe. The transducer was placed in an area between anterior axillar line and midclavicular line and using the liver as ultrasound window directed toward the diaphragmatic dome. The participant was instructed to exhale as deeply as possible

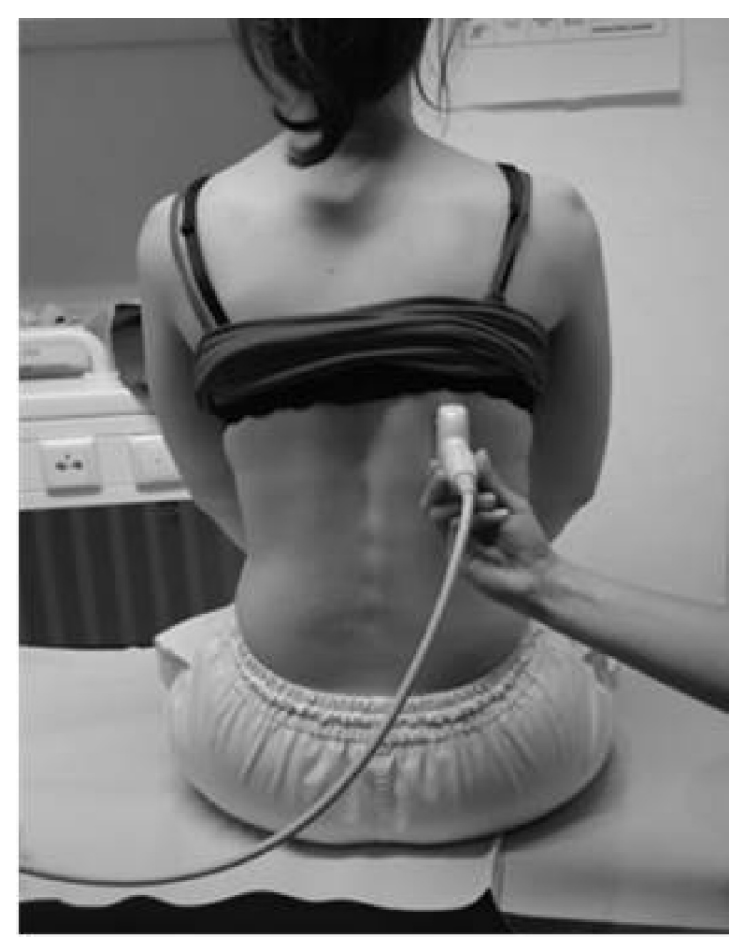

Figure I Sonographic measurement of the up- and downward movement of the lung silhouette - here on the right side.

Notes: The patient is sitting; the transducer is placed at the lowest point of the lung silhouette in the scapular line. While the patient breathes as deeply as possible a video sequence is performed. Afterward the distance between maximal inspiration and maximal expiration can be measured. 

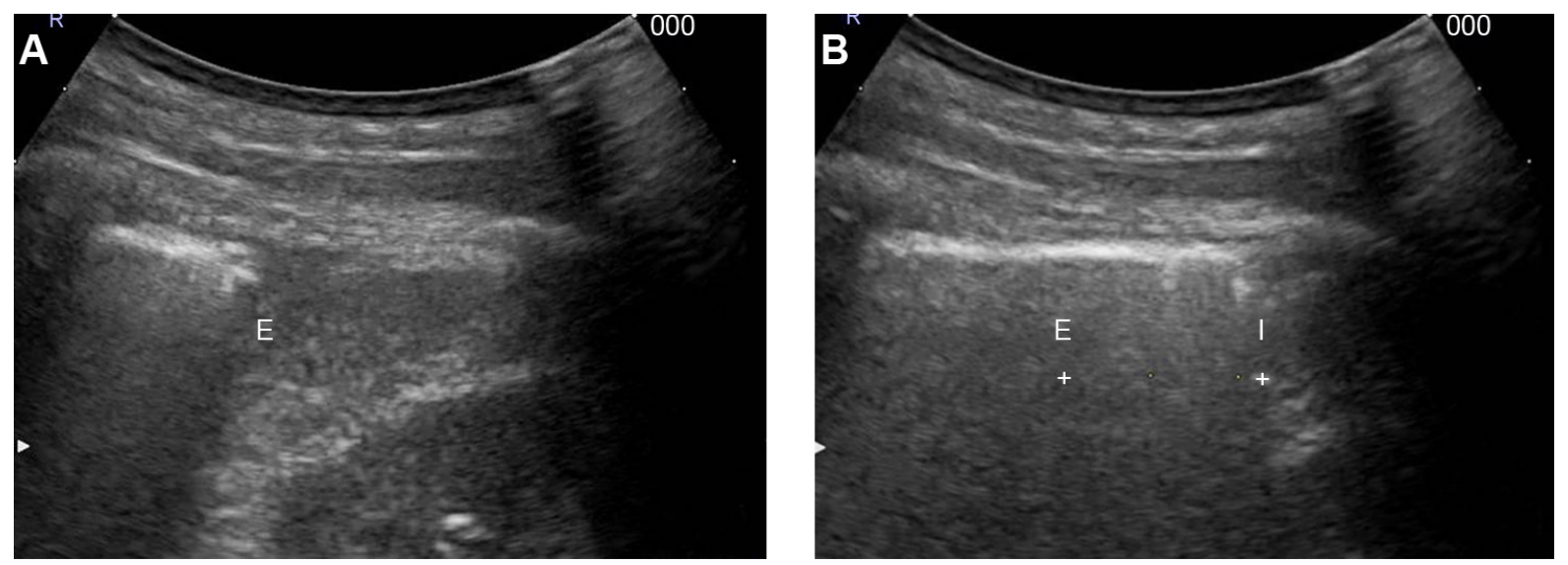

Figure 2 Sonografic measurement of the maximum lung movement.

Notes: (A) Sonographic measurement of the up- and downward movement of the lung silhouette - here on the right side. E marks the lowest point of the lung silhouette at maximal end expiration. (B) Sonographic measurement of the up- and downward movement of the lung silhouette - here on the right side. E marks the lowest point of the lung silhouette at maximal end expiration, and I marks the lowest point at maximal inspiration. In this example, the distance between $\mathrm{E}$ and $\mathrm{I}$ is $28 \mathrm{~mm}$.

(to RV) and then to inhale deeply to total lung capacity. This maneuver was filmed, and afterward, the distance between the highest and the lowest point of the right hemidiaphragmatic dome was measured. This method was used only on the right side because of the known difficulties with the measurement on the left side with the spleen as ultrasound window. ${ }^{20,21,24,27,29}$

\section{Data analysis}

Data analysis was done with SPSS (IBM Corporation, Armonk, NY, USA), and correlation coefficient ( $r$ ) was determined according to Spearman-rho.

\section{Results}

Eighty participants were investigated. The selection of the participants was randomly done according to the inclusion and exclusion criteria until 20 participants were included into each group.

\section{Correlation between the sonographic methods}

The correlation between the lung silhouette method (the measurement of the up- and downward movement of the lung silhouette in the scapular line - mean of both hemidiaphragms) and the anterior method (the direct visualization of the right diaphragmatic dome from the anterior axillary line) is strong: $r=0.85$ (Figure 3 ).

We also looked at the separate measurements of the diaphragmatic movement of the right and the left hemidiaphragm. In our study group, the correlation between both is strong: $r=0.89$.

Furthermore, we looked into the correlation between the two methods of the right hemidiaphragmatic movement in the different patient groups. In the COPD GOLD II patient group, the median distance of the up- and downward movement of the right hemidiaphragm measured with the lung silhouette method was $43 \mathrm{~mm}$ and measured with the anterior method was $46 \mathrm{~mm}$. In the COPD GOLD III patient group, the respective results were $30 \mathrm{~mm}$ and $37 \mathrm{~mm}$; in the GOLD IV patient group, $25 \mathrm{~mm}$ and $31 \mathrm{~mm}$ and in the control group $65 \mathrm{~mm}$ and $68 \mathrm{~mm}$ (Table 1).

\section{Diaphragmatic movement and other parameters}

Additionally we were interested in the correlation of our median diaphragmatic movement measured with the silhouette method with other ventilator and respiratory

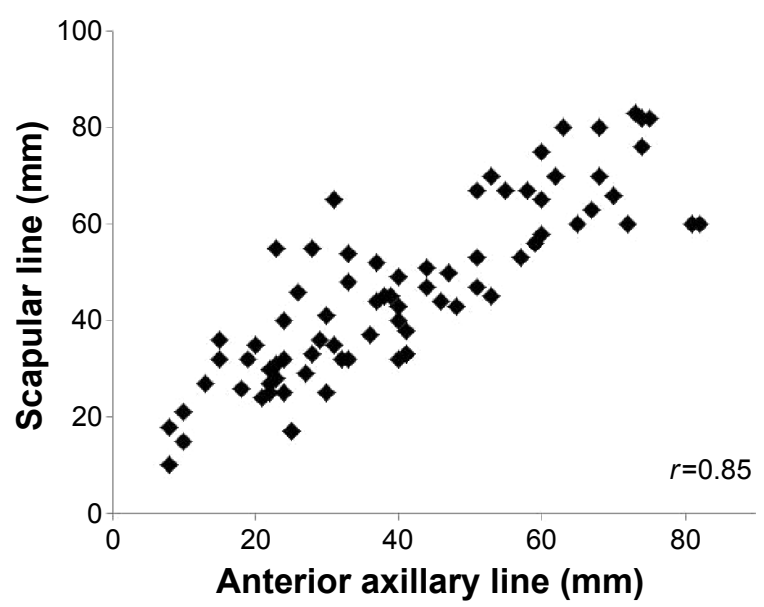

Figure 3 Correlation of both sonographic measurements of diaphragmatic movement of the right hemidiaphragm.

Notes: Scapular line means the sonographically measured distance of the lung silhouette movement between deep inhalation and deep exhalation on the right hemidiaphragm. Anterior axillary line means the sonographic measurement of the diaphragm dome with the liver used as ultrasound window. Correlation is high $(r=0.85)$. 
Table I Diaphragmatic movement measured using the lung silhouette method and the anterior method in the different patient groups

\begin{tabular}{lll}
\hline & Lung silhouette $\mathbf{( m m})$ & Anterior $\mathbf{( m m})$ \\
\hline COPD II & 43 & 46 \\
COPD III & 30 & 37 \\
COPD IV & 25 & 31 \\
Control group & 65 & 68 \\
\hline
\end{tabular}

Abbreviation: COPD, chronic obstructive pulmonary disease.

parameters. The correlation of the diaphragmatic movement and FEV1 was strong: $r=0.83$ (Figure 4).

The correlation with the VC was strong: $r=0.70$. The correlation with the RV was strong: $r=-0.71$. The correlation with $\mathrm{CO}$ diffusion capacity was strong: $r=0.81$. The correlation with P0.1/Pimax was moderate: $r=-0.41$. The correlation with $\mathrm{pO}_{2}$ was weak: $r=0.13$. The correlation with $\mathrm{pCO}_{2}$ was moderate: $r=-0.47$. The correlation with $\mathrm{pH}$ was weak: $r=0.11$. The correlation with breathing frequency was moderate: $r=-0.47$.

The correlation with distance walked in the 6-minute walk test was moderate: $r=0.67$.

\section{Discussion}

We demonstrate our method of the evaluation of diaphragmatic dysfunction: the measurement of the upward and downward movement of the lung silhouette in the scapular line. This method is somewhat similar to the old fashioned method of lung percussion - now with technical support. We

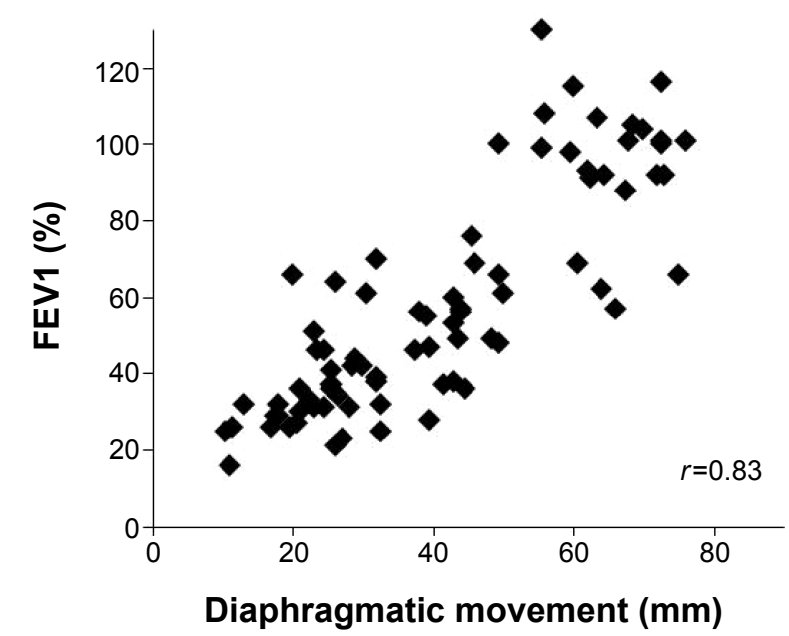

Figure 4 Correlation of diaphragmatic movement and FEVI in COPD patients and healthy volunteers.

Notes: The diaphragmatic movement was measured sonographically by the distance of the lung silhouette movement between deep inhalation and deep exhalation of both hemidiaphragms. For each patient, the medium of the measured distances of both hemidiaphragms was calculated. Correlation is high ( $r=0.83$ ).

Abbreviations: FEVI, forced expiratory volume in the first second; COPD, chronic obstructive pulmonary disease. demonstrate that this method is easy to perform and produces reliable results in all of the selected 80 patients who fulfilled the inclusion criteria.

We could demonstrate that this measurement of the upand downward movement of the lung silhouette gives comparable results to another potential sonographic methods to measure diaphragmatic dysfunction, the direct visualization of the up- and downward movement of the diaphragmatic dome from the anterior axillar line using the liver as an ultrasound window. We compared the results of our control group with the data from Boussuges et al. ${ }^{27}$ Boussuges et al could successfully measure the maximal diaphragmatic excursion during deep breathing on the right hemidiaphragm in 195 from 210 patients (93\%) but on the left in only 45 from 210 patients (23\%). The mean excursion in their study was $6.6 \mathrm{~cm}$ on the right hemidiaphragm and $7.3 \mathrm{~cm}$ on the left hemidiaphragm. Our results are similar: using the same method as Boussuges, we could successfully use this method in 78 out of our 80 patients and the mean distance measured in our control group was $6.8 \mathrm{~cm}$ on the right side. Measurement of the downward movement of the lung silhouette on the right side in the patients of our control group resulted in a medium distance of $6.5 \mathrm{~cm}$.

The measurement of the medium diaphragmatic movement is slightly lower than the alternative measurement with the liver as an ultrasound window, but it is well known that different parts of the diaphragm move very differently during inhalation and exhalation. For example, the anterior parts of the diaphragm move less downward. ${ }^{30}$ This depends at least partly on the parallel anterior and upward movement of the ribcage during a deep inspiration, especially in COPD patients who are used to using their accessory inspiration muscles. So every method visualizing the movement of a single point of the diaphragm never measures the total diaphragmatic movement. The differences in the distances measured by different methods are not only acceptable but also logical.

The sonographic methods are good surrogate markers of the diaphragm force. And we will continue using the up- and downward movement of the lung silhouette because 1) it correlates very well with a comparative method (the visualization of the diaphragm from anterior); 2) it is easy to perform; 3 ) it can be done in every patient (even in the very obese ones), and 4) it can almost always be performed on both hemidiaphragms.

Another important result of our study is the strong correlation between FEV1 and diaphragmatic movement. The correlation is not $100 \%$. This was not to be expected because we already know that different types of emphysemas 
result in different degrees of diaphragmatic dysfunction. For example, a more severe diaphragmatic dysfunction has been described for the basal predominant emphysemas compared to the apical predominant emphysemas. ${ }^{31}$ Interestingly, patients with basally pronounced emphysemas and thus more severe diaphragmatic dysfunction have a lower life expectancy ${ }^{32,33}$ But nevertheless, the measurement of the diaphragmatic movement cannot substitute for lung function tests. It is an additional test, especially if methods need to be tested to improve diaphragmatic weakness: it is useful 1) to control the effect of medical trials testing different medications designated to improve the diaphragmatic weakness like levosimendan ${ }^{34,35}$ or bortezomib; ${ }^{36}$ 2) to control the effects of rehabilitation programs or inspiratory muscle training on the diaphragm; or 3) to visualize the effects of endobronchial lung volume reduction therapy.

The correlation of the diaphragmatic dysfunction to other lung function parameters than FEV1 is weaker. But there is a tendency of a more severe diaphragmatic dysfunction if the $\mathrm{RV}$ is higher, and the more pronounced the diaphragmatic weakness is the lower is the VC probably mainly as a result of lung overinflation.

We could demonstrate that sonographic measurement of the upward and downward movement of the lung silhouette in the scapular line is a reliable method to measure diaphragmatic dysfunction in COPD patients. If this method of the measurement of diaphragmatic dysfunction is also a reliable method in patients who are more difficult to investigate, like the very obese patients and patients undergoing weaning from the ventilator, needs to be investigated. Our own experience, especially in patients undergoing weaning from the ventilator let us expect that this sonographic method is successful in these patients too. We think that sonographic measurement of the diaphragmatic movement will become a strong addition to lung function parameters in the evaluation of ventilatory muscle strength.

\section{Disclosure}

For all authors, there is no potential conflict of interest existing with any companies/organizations whose products or services may be discussed in this paper.

\section{References}

1. Similowski T, Yan S, Gauthier AP, Macklem PT, Bellemare F. Contractile properties of the human diaphragm during chronic hyperinflation. $N$ Engl J Med. 1991;325(13):917-923.

2. Laghi F, Tobin MJ. Disorders of the respiratory muscles. Am J Respir Crit Care Med. 2003;168(1):10-48.

3. Decramer M. Effects of hyperinflation on the respiratory muscles. Eur Respir J. 1989;2(4):299-302.
4. Tzelepis G, McCool FD, Leith DE, Hoppin FG Jr. Increased lung volume limits endurance of inspiratory muscles. J Appl Physiol. 1988;64(5):1796-1802.

5. Levine S, Nguyen T, Kaiser LR, et al. Human diaphragm remodeling associated with chronic obstructive pulmonary disease: clinical implications. Am J Respir Crit Care Med. 2003;168(6):706-713.

6. Barreiro E, de la Puente B, Minguella J, et al. Oxidative stress and respiratory muscle dysfunction in severe chronic obstructive pulmonary disease. Am J Respir Crit Care Med. 2005;171(10):1116-1124.

7. Ottenheijm CA, Heunks LM, Sieck GC, et al. Diaphragm dysfunction in chronic obstructive pulmonary disease. Am J Respir Crit Care Med. 2005;172(2):200-205.

8. Ottenheijm CA, Heunks LM, Li YP, et al. Activation of the ubiquitinproteasome pathway in the diaphragm in chronic obstructive pulmonary disease. Am J Respir Crit Care Med. 2006;174(9):997-1002.

9. Laghi F, Topeli A, Tobin MJ. Does resistive loading decrease diaphragmatic contractility before task failure? J Appl Physiol. 1998;85(3): $1103-1112$

10. Man WD, Moxham J, Polkey MI. Magnetic stimulation for the measurement of respiratory and skeletal muscle function. Eur Respir J. 2004; 24(5):846-860.

11. Wragg S, Hamnegard C, Road J, et al. Potentiation of diaphragmatic twitch after voluntary contraction in normal subjects. Thorax. 1994;49(12): 1234-1237.

12. Bellemare F, Cordeau MP, Couture J, Lafontaine E, Leblanc P, Passerini L. Effects of emphysema and lung volume reduction surgery on transdiaphragmatic pressure and diaphragm length. Chest. 2002;121(6): 1898-1910.

13. Polkey MI, Kyroussis D, Hamnegard CH, Mills GH, Green M, Moxham J. Diaphragm strength in chronic obstructive pulmonary disease. Am J Respir Crit Care Med. 1996;154(5):1310-1317.

14. Criner G, Cordova FC, Leyenson V, et al. Effect of lung volume reduction surgery on diaphragm strength. Am J Respir Crit Care Med. 1998; 157(5Pt1):1578-1585.

15. Jalinous R. Technical and practical aspects of magnetic nerve stimulation. J Clin Neurophysiol. 1991;8(1):10-25.

16. Lahgi F, Shaik HS, Morales D, Sinderby C, Jubran A, Tobin MJ. Diaphragmatic neuromechanical coupling and mechanisms of hypercapnia during inspiratory loading. Respir Physiol Neurobiol. 2014;198:32-41.

17. Ch'en IY, Armstrong JD 2nd. Value of fluoroscopy in patients with suspected bilateral hemidiaphragmatic paralysis. Am J Roentgenol. 1993; 160(1):29-31,

18. Iwasawa $\mathrm{T}$, Kagei $\mathrm{S}$, Gotoh $\mathrm{T}$, et al. Magnetic resonance analysis of abnormal diaphragmatic motion in patients with emphysema. Eur Respir J. 2002;19(2):225-231.

19. Plathow C, Schoebinger M, Fink C, et al. Evaluation of lung volumetry using dynamic three-dimensional magnetic resonance imaging. Invest Radiol. 2005;40(3):173-179.

20. Ueki J, De Bruin PF, Pride NB. In vivo assessment of diaphragm contraction by ultrasound in normal subjects. Thorax. 1995;50(11):1157-1161.

21. Cohn D, Benditt JO, Eveloff S, McCool FD. Diaphragm thickening during inspiration. J Appl Physiol. 1997;83(1):291-296.

22. Gottesman E, McCool FD. Ultrasound evaluation of the paralyzed diaphragm. Am J Respir Crit Care Med. 1997;155(5):1570-1574.

23. Yamaguti WP, Paulin E, Salge JM, Chammas MC, Cukier A, de Carvalho CR. Diaphragmatic dysfunction and mortality in patients with COPD. J Bras Pneumol. 2009;35(12):1174-1181.

24. Toledo NS, Kodaira SK, Massarollo PC, Pereira OI, Mies S. Right hemidiaphragmatic mobility: assessment with US measurement of craniocaudal displacement of left branches of portal vein. Radiology. 2003; 228(2):389-394.

25. Houston JG, Fleet M, Cowan MD, McMillan NC. Comparison of ultrasound with fluoroscopy in the assessment of suspected hemidiaphragmatic movement abnormality. Clin Radiol. 1995;50(2):95-98.

26. McCauley RG, Labib KB. Diaphragmatic paralysis evaluated by phrenic nerve stimulation during fluoroscopy or realtime ultrasound. Radiology. 1984;153(1):33-36. 
27. Boussuges A, Gole Y, Blanc P. Diaphragmatic motion studied by m-mode ultrasonography: methods, reproducibility, and normal values. Chest.2009; 135(2):391-400.

28. Houston JG, Angus RM, Cowan MD, McMillan NC, Thomson NC. Ultrasound assessment of normal hemidiaphragmatic movement: relation to inspiratory volume. Thorax. 1994;49(5):500-503.

29. Houston JG, Morris AD, Howie CA, Reid JL, McMillan N. Technical report: quantitative assessment of diaphragmatic movement - a reproducible method using ultrasound. Clin Radiol. 1992;46(6):405-407.

30. Verschakalen JA, Deschepper K, Jiang TX, Demedts M. Diaphragmatic displacement measured by fluoroscopy and derived by Respitrace. J Appl Physiol. 1989;67(2):694-698.

31. Iwasawa T, Takahashi H, Ogura T, et al. Influence of the distribution of emphysema on diaphragmatic motion in patients with chronic obstructive pulmonary disease. Jpn J Radiol. 2011;29(4):256-264.

32. Parr DG, Stoel BC, Stolk J, Stockley RA. Pattern of emphysema distribution in alpha1-antitrypsin deficiency influences lung function impairment. Am J Respir Crit Care Med. 2004;170(11):1172-1178.
33. Martinez FJ, Foster G, Curtis JL, NETT Research Group, et al. Predictors of mortality in patients with emphysema and severe airflow obstruction. Am J Respir Crit Care Med. 2006;173(12):1326-1334.

34. van Hees HW, Dekhuijzen PN, Heunks LM. Levosimendan enhances force generation of diaphragm muscle from patients with chronic obstructive pulmonary disease. Am J Respir Crit Care Med. 2009;179(1): 41- 47 .

35. Doorduin J, Sinderby CA, Beck J, et al. The calcium sensitizer levosimendan improves human diaphragm function. Am J Respir Crit Care Med. 2012;185(1):90-95.

36. van Hees H, Ottenheijm C, Ennen L, Linkels M, Dekhuijzen R, Heunks L. Proteasome inhibition improves diaphragm function in an animal model for COPD. Am J Physiol Lung Cell Mol Physiol. 2011;301(1): L110-L116.

\section{Publish your work in this journal}

The International Journal of COPD is an international, peer-reviewed journal of therapeutics and pharmacology focusing on concise rapid reporting of clinical studies and reviews in COPD. Special focus is given to the pathophysiological processes underlying the disease, intervention programs, patient focused education, and self management protocols.

\section{Dovepress}

This journal is indexed on PubMed Central, MedLine and CAS. The manuscript management system is completely online and includes a very quick and fair peer-review system, which is all easy to use. Visit http://www.dovepress.com/testimonials.php to read real quotes from published authors. 